\title{
Memória, fronteiras e discursos: o corpo em cenas prototípicas de protestos feministas
}

\author{
Emanuel Angelo Nascimento \\ Universidade Estadual de Campinas (UNICAMP), Campinas, São Paulo, Brasil \\ emanuellangelo@yahoo.com.br \\ http://orcid.org/0000-0001-6380-4792
}

DOI: http://dx.doi.org/10.21165/el.v47i3.1921

\begin{abstract}
Resumo
Este artigo se desdobra sob a perspectiva do materialismo-histórico e, tendo como base o dispositivo teórico da Análise do Discurso francesa, visa analisar a materialidade significante do corpo na relação corpo, memória e discurso, em cenas prototípicas de protestos feministas, observando os movimentos dos discursos na relação com os sentidos pré-construídos que se colocam na fronteira entre a evidência e a opacidade. Assim, ao trabalhar com a imbricação entre a materialidade verbal e não-verbal (ORLANDI, 1995) que produzem efeitos de sentido que deslizam metafórica e metonimicamente para outros sentidos, analisamos as formulações visuais do corpo que se desdobram em diferentes imagens do sujeito (LAGAZZI, 2014a), tendo em vista os processos de estruturação do conflito e da tensividade do/no social a partir dos espaços ocupados por estes corpos e atravessados que são pelo simbólico, pela ideologia e pela história.
\end{abstract}

Palavras-chave: cenas prototípicas; corpo; discurso feminista.

\section{Mémoire, frontières et discours: le corps dans des scènes prototypiques de protestations féministes}

\section{Résumé}

Cet article se déroule sur la perspective du matérialisme historique et basé sur le dispositif théorique de l'analyse du discours française vise à analyser la matérialité signifiante du corps dans la relation corps-mémoire-discours, dans certaines scènes prototypiques de protestations féministes. Nous cherchons à observer les mouvements du discours par rapport à les preconstruites qui se posent à la frontière entre l'évidence et l'opacité. Ainsi, en considérant l'imbrication entre la matérialité verbale et non verbale (ORLANDI, 1995) qui produisent des effets de sens qui glissent métaphoriquement et métonymique à d'autres sens, nous analysons les formulations visuelles de corps qui se déroulent dans différentes portraits du sujet (LAGAZZI, 2014a), compte tenu des processus de structuration de la tensivité du/dans le social à partir des espaces ocupés par des corps et traversés qu'ils sont par la symbolique, par l'idéologie et par l'histoire.

Mots-clés: scènes prototypiques; corps; discours féministe.

\section{Introdução}

Pensar no/sobre o corpo discursivamente é levar em conta os processos de significação que o constituem no movimento dos sentidos, especialmente, na relação entre a subjetividade, a memória, o discurso e os protestos feministas, em diferente(s) espaço(s) - aberto(s), fechado(s), público(s). Corpo e discurso atravessados que são pela 
ideologia, pela história e pelo simbólico se intercruzam e se deslocam em constante movimento de significação. Há, desse modo, o corpo que luta, há o corpo que se lança, há o corpo na luta. Há, igualmente, o corpo em/na militância, há o corpo que milita e há o corpo que não se cansa, significando, nos fios do discurso, diferentemente. Pensar na materialidade significante do corpo é, assim, considerar também como diferentes discursos (res)significam o corpo e como este se coloca nas fronteiras com o social.

Nesse sentido, partimos dos pressupostos teóricos da Análise do Discurso francesa, sob a perspectiva do materialismo-histórico de base pêcheutiana, especialmente aquela praticada por Eni Orlandi e por Suzy Lagazzi, a fim de observar os movimentos de sentido, no que diz respeito às diferentes relações entre corpo, memória, discurso e protesto. Para tanto, procedemos a um recorte em um conjunto de imagens de protestos realizados por grupos feministas ao longo da história até os dias atuais.

A discursividade dos protestos feministas é um importante ponto de entrada no percurso analítico aqui proposto. Procedemos, desse modo, no desafio de nos lançarmos em gestos de interpretação das imagens do corpo feminino/feminista em/no protesto. Protestos do feminino e protestos feministas, que significam e produzem diferentes sentidos neste corpo, sobre este corpo, a partir dele e através dele. Procuramos, a partir desse ponto de ancoragem, trazer à baila as reflexões feitas por Michel Pêcheux, quando o autor traz uma importante questão: 'abstrações como 'o povo', 'as massas', 'o proletariado', 'a luta de classes' podem ser mostradas (pintadas, filmadas ou televisionadas) enquanto conceito, sem disfarces?" (PÊCHEUX, 1990b [1982], p. 54).

Enquanto materialidade significante, a imagem funciona como um dispositivo, bem como um "operador da memória social" (PECHEUX, 1984) e da memória discursiva. Nesse sentido, nosso percurso analítico é afetado pelos efeitos de sentido demandados pelos gestos teórico-analíticos de descrição e interpretação das imagens que constituem o nosso corpus de análise. Tais gestos de leitura demandam do analista caminhos de interpretação que mobilizam deslocamentos a partir do investimento sobre o objeto de estudo, isto tendo como ponto de ancoragem o olhar lançado sobre este corpo que significa diferentemente, dadas as condições de produção do sentido que o envolve e o norteia enquanto objeto simbólico atravessado pelo discurso, pela história e pela ideologia.

\section{Formulações visuais do corpo enquanto suporte do discurso}

Ao investirmos na análise das formulações visuais, considerando a materialidade significante do corpo na discursividade dos protestos feministas, levamos em conta as condições de produção do sentido, a exemplo do espectro da câmera, que captura a imagem, que filtra e apaga outros sentidos. Para tanto, mobilizamos alguns conceitos importantes, tais como o de "deslinearização da imagem" e de "formulação visual"

\footnotetext{
1 Tradução para o português de José Horta Nunes, a partir do original em francês: “des abstractions comme « le peuple », « les masses », « le prolétariat », « la lutte des classes » peuvent-elles être montrées (peintes, filmées ou télévisées) à l'état de concept, sans travestissement?”.
} 
associados à noção de “composição material”, conforme proposto por Suzy Lagazzi², principalmente, quando a autora insiste no investimento analítico sobre "as formulações visuais do corpo que se desdobram em diferentes imagens do sujeito e nos mostram a importância da remissão do intradiscurso ao interdiscurso para compreender a textualização das imagens" (LAGAZZI, 2014a, p. 111).

Suzy Lagazzi, assim, examinando alguns recortes de imagem extraídos de filmes e documentários, assinala a importância de se discutir a questão do corpo no social, observando os sentidos em torno da imagem nos processos de metaforização metonímica, a fim de melhor compreender os trajetos de memória e de discursivização do corpo. Nesse sentido, também compartilhamos, por exemplo, das reflexões de Eni Orlandi, que, em seus trabalhos, a partir da perspectiva materialista discursiva, engedra um olhar atento aos discursos mobilizados na rua e nos espaços públicos, pois, segundo a autora, trata-se um gesto que busca "compreender como os discursos se textualizam neste espaço de interpretação"3 (ORLANDI, 2001, p. 117).

Desse modo, as cenas de protestos feministas, a partir das quais fazemos um investimento analítico, considerando a sua discursividade e o seu acontecimento, podem ser entendidas, de acordo com as reflexões de Pêcheux (1984), como um ponto de encontro entre a atualidade e a memória. O feminino no feminismo e o feminismo enquanto discurso atravessado pela materialidade significante do corpo (do) feminino significam historicamente de forma diferente, considerando as diferentes condições de produção, em especial, a discursividade dos protestos feministas, em que sujeito(s) e sentido(s) são interpelados pela ideologia. Assim, considerando a materialidade do sujeito, o corpo significa discursiva e ideologicamente. De acordo com Orlandi (2012, p. 83), "a significação do corpo não pode ser pensada sem a materialidade do sujeito. E vice-versa, ou seja, não podemos pensar a materialidade do sujeito sem pensar sua relação com o corpo".

Tendo isso em vista, no coletivo heterogêneo do social, as formulações visuais do corpo se encontram com outros corpos - alguns, muitas vezes, em união, em/no conflito ou tomados que são pela tensividade do combate, das lutas n(d)o social, outras vezes, interligados ou em dispersão (nas ruas, nos espaços públicos, nas redes sociais). Corpo e discurso se revelam, nesses casos, como movimentos de resistência e de luta (social, política, militante e simbólica) sempre em movimento. Movimento esse que se coloca nas fronteiras dos corpos, dos espaços e da memória.

\section{Corpo(s) heterogêneo(s) do/no discurso feminista}

As imagens que pretendemos analisar a partir deste artigo demandam diferentes gestos de descrição na/pela relação entre corpo e discurso enquanto forças de luta e resistência política, histórica e simbólica. Estes corpos do feminino em protestos se encontram com outros corpos, muitas vezes, em combate. Assim, é no interdiscurso que

\footnotetext{
2 Suzy Lagazzi, no capítulo "Metaforizações metonímicas do social", do livro Linguagem, sociedade, políticas (2014a), propõe um investimento analítico na deslinearização da imagem, entre outros objetivos, também o de compreender o acontecimento simbólico do corpo discursivizando o social.

3 Tradução nossa a partir do original em francês: "comprendre comment les discours se textualisent dans cet espace d'interprétation".
} 
eles se constituem pela/na corporalidade como suporte discursivo e ideológico. Segundo uma perspectiva de sociedade operante enquanto coletivo, este(s) corpo(s) femini(stas/nos) decorre(m), em geral,

[...] dos processos de socialização que determinam os grupos humanos, assegurando com certa coerência a ideia de institucionalização e de forma inversa sendo percebido como fonte de um possível deslocamento do sentimento de identidade profissional ou social (HAROCHE; GUGLIELMI, 2005, p. 5). ${ }^{4}$

A partir disto - sobretudo considerando a análise de algumas cenas de protestos feministas que faremos a seguir - é importante levar em conta também uma certa perspectiva sociológica do corpo, tal como propõe David Le Breton, que reflete que "o corpo é socialmente construído, tanto nas suas ações sobre a cena coletiva quanto nas teorias que explicam seu funcionamento" (LE BRETON, 1992, p. 29).

Assim, observando o histórico dos protestos organizados por militantes de diversos grupos feministas - a exemplo das feministas suffraGETtes (na virada do século XIX para o século XX, na Inglaterra), das ativistas do Movimento Feminino pela Anistia contra o regime militar, sob liderança da advogada e assistente social Terezinha Zerbini (na década de 70, no Brasil) e dos movimentos organizados, nos dias atuais, pelo grupo Femen, no Brasil e na Europa - é possível compreender, sócio, histórica e discursivamente, os diferentes movimentos de subjetividade e de inscrição do corpo feminino na heterogeneidade ideológica e discursiva do feminismo, enquanto entrelaçamento de corpos colocados nas fronteiras do(s) sentido(s).

Não por acaso, o Femen se tornou internacionalmente conhecido por organizar diversos protestos de militantes femini(n/t)as seins nus (com os seios expostos) acompanhados de inscrições no próprio corpo, no intuito de defender, entre diversas causas, os direitos das mulheres - bem como chamar a atenção para temas relevantes como o da democracia feminina, o da prostituição, o do feminicídio, o da exploração da imagem da mulher e do abuso contra mulheres, além de questões como o da influência religiosa na sociedade, inicialmente na Ucrânia pós-soviética, extendendo-se para o contexto europeu e internacional contemporâneo de forma geral. Nesse sentido, os protestos desse grupo, nos dias atuais, podem ser compreendidos seja na perspectiva histórica, sociológica, bem como na/pela perspectiva discursiva, enquanto manifestação coletiva constituída por diferentes corpos atravessados pela memória e pela ideologia que se coloca $(\mathrm{m})$ nas fronteiras entre o político e o social. É nesse entendimento que compreendemos esse corpo heterogêneo enquanto suporte de discurso nos diferentes modos pelos quais a corporalidade é formulada e atravessada por dizeres e imagens de si no confronto com o discurso do outro ${ }^{5}$.

\footnotetext{
${ }^{4}$ Tradução nossa para o português a partir do original em língua francesa: "Il relève des processus de socialisation qui déterminent tous les groupes humains, il assure d'une certaine cohérence l'idée d'institutionnalisation et à l'inverse est perçu comme à l'origine d'un possible dévoiement du sentiment d'identité professionnelle ou sociale".

${ }^{5}$ A materialidade do social interpelada pelo discurso do outro, nesse sentido, trata-se daquilo que Pêcheux (1990s) considera como a insistência do outro enquanto leis dos espaços sociais e da memória histórica e política.
} 


\section{A materialidade significante do corpo e do corpus em análise}

Considerando a importância da/na seleção de um corpus enquanto procedimento essencial do analista de discurso, mobilizamos aqui um dos critérios metodológicos de pré-análise do corpus, tal como orienta Orlandi (1990).

Um destes critérios se baseia na extração/extrações a partir de um universal de discurso, o que implica exclusões, filtros de análise e a predileção por determinado(s) discurso(s) por parte do(s) analista(s), como é o caso da discursividade dos protestos feministas aqui escolhidos. Quanto a esse método de levantamento e organização do corpus, consideramos, bem como destaca Eni Orlandi (1990, p. 63), que há uma paisagem:

[...] inicial fundamental que é a que se faz entre a superfície linguística (o material bruto de linguagem bruto coletado, tal como existe) e o objeto discursivo, sendo este definido pelo fato de que o corpus já recebeu um primeiro tratamento de análise superficial, feito em uma primeira instância, pelo analista, e já se encontra desuperficializado.

Nesse sentido, levamos em conta a heterogeneidade dos planos de estruturação do nosso corpus e, em termos de procedimento analítico, investimos em "diferentes gestos de leitura que constituem os sentidos" (ORLANDI, 1990, p. 65) do objeto submetido à análise - que, no caso de material aqui levantado, selecionado e organizado, compreende a materialidade de imagens (fotografias, fotogramas) de cenas de protestos feministas desde o século XIX (especialmente a partir das décadas de 60, 70, 80 em diante) até os diais atuais. Para tanto, consideramos também a imbricação entre o verbal e o não-verbal, a partir da materialidade linguística (frases, slogans, dizeres) presentes nestas imagens.

Desse modo, pensar o(s) movimento(s) feminista(s), no Brasil e no mundo, é buscar compreender as caracterizações do feminismo marcadas por uma série de manifestações (heterogêneas) que ganharam força no final do século XIX, na Inglaterra, na luta por igualdade política, cultural, sexual e social para as mulheres e em favor de seus direitos. Esse(s) movimento(s), de acordo com Blay $(2001)^{6}$, se desdobrou(aram) em três momentos, a saber:

(i) o da primeira onda dos movimentos feministas, nas ruas de Londres, na virada do século XIX para o século XX, passando por marcos como a conquista do direito ao voto pelas mulheres, no Reino Unido, 1918, e, por exemplo, a publicação, em 1949, na França, da obra inédita $O$ segundo sexo, de Simone de Beauvoir, traduzida para mais de 30 línguas;

\footnotetext{
6 Eva Alterman Blay é professora do departamento de Sociologia da FFLCH-USP e coordenadora científica do Núcleo de Estudos da Mulher e Relações Sociais de Gênero (Nemge-USP).
} 
(ii) pós-anos 60 até a década de 80 , período ${ }^{7}$ que foi marcado pela expansão dos movimentos feministas pelo mundo e, a partir do qual, as demandas feministas passaram a ter fortes críticas à condição de submissão da mulher ao pensamento e comportamento patriarcalista e à heterossexualidade como "norma" e condição social da mulher restrita, em geral, aos papéis de mãe e esposa;

(iii) e período pós anos 90, tendo continuidade nos anos 2000, marcando a terceira onda do movimento feminista, que é considerada uma ampliação das lutas travadas nos anos anteriores, e que abriu espaço para a discussão de temas como aborto, liberdade sexual, corpo feminino, adoção, salto alto, decotes e batom ganham espaço com a tônica de que é possível ser feminina, forte, lutando contra alguns estereótipos e rótulos em torno da figura da mulher - o que favoreceu o crescimento de protestos feministas promovidos por grupos organizados e anônimos em diversos países, a exemplo do grupo Femen internacional (de origem Ucraniana, fundado, em 2008, em Kiev, na Ucrânia, por Anna Hutsol, e cuja sede atualmente está localizada na França, em Paris).

No Brasil, a partir dessa terceira onda, a luta para combater a violência contra a mulher, tais como a violência doméstica, culminou em conquistas com a Lei Maria da Penha 11.340 de 7/10/2006. Além disso, com o advento das redes sociais, as ativistas políticas e feministas têm atuado militantemente, ocupando os espaços digitais e as ruas em protestos pelos direitos das mulheres e contra diversas pautas, entre as quais, a ditadura da opressão ao corpo da mulher.

$\mathrm{Na}$ era das redes sociais, algumas estudiosas, assim como Marie-Anne e Stéphanie Pahud, vêm se debruçando em seus trabalhos sobre o que se tem se chamado de quarta onda feminista.

(iv) pensando na chamada quarta onda feminista, de acordo com França (2016, p. 95), "a questão do corpo no digital tem sido objeto de reflexão, em especial no âmbito de discussões de gênero e sobre os feminismos, a esse respeito formula-se o fato dessa presença e dessa militância pelo/com o corpo ser até mesmo uma das características que identificaria uma nova "onda", ou fase, nos feminismos". A autora traz para as discussões o pensamento de Marie-Anne Paveau, que chama de quarta onda feminista "esse momento da militância que usa das diversas ferramentas possíveis disponibilizadas pelo digital" (PAVEAU, 2014 apud FRANÇA, 2016, p. 95). No ciberespaço, as mulheres passaram a ocupar espaços de resistência colocando em pauta diversas demandas. Assim, segundo Dantielli Assumpção Garcia (2018, p. 25), "foi na internet que seus dizeres ecoaram mais fortemente. Algumas hashtags como \#PrimeiroAssédio, \#MeuAmigoSecreto e \#AgoraÉqueSãoElas viralizaram na rede e contribuíram para um debate que girava em torno de feminismo, preconceito, igualdade de direitos e salários, entre outros". Nesse período da chamada quarta onda, surgiram diferentes grupos feministas, no Brasil e no mundo (alguns anônimos e outros organizados), tais como o grupo internacional Femen, o Femen Brazil, a Universidade

\footnotetext{
${ }^{7}$ Nesse período, também se destacaram como símbolos e marcos do movimento feminista a obra da ativista norte-americana Betty Friedan (1921-2006), a I Conferência Internacional da Mulher organizada, no México, em 1975, pela ONU. Enquanto isso, no Brasil, no mesmo ano, foi lançado o Movimento Feminino pela Anistia contra o regime militar, sob a liderança da advogada e assistente social Terezinha Zerbini (1928-2015) e a obra da escritora e militante política Patrícia Rehder Galvão (1910-1962), conhecida pelo pseudônimo de Pagu, que ganhou destaque por sua atuação em favor do feminismo e por seu comportamento ousado à época, que rompia com alguns dos padrões da mulher do século XX.
} 
Livre Feminista, o Coletivo Feminista Rosa Lilás, o Coletivo Feminista Histéricas da FEA-USP, entre outros. Um movimento que ganhou bastante repercussão e se popularizou foram as Slutwalks (Marchas das Vadias), que surgiram a partir de um protesto realizado no dia 3 de abril de 2011, em Toronto, no Canadá. A primeira Marcha das Vadias, no Brasil, foi organizada, nas redes sociais, pela publicitária curitibana Madô Lopez e a escritora paraguaia Solange De-Ré, e ocorreu nas ruas de São Paulo (SP), em 4 de junho de 2011. Deste ano em diante, iniciam-se diversas marchas em Recife (PE), Belo Horizonte (MG), Brasília (DF), Itabuna (BA) e São José do Rio Preto (SP).

Ainda que estes movimentos sejam constituídos, desde as ondas anteriores, por feministas que buscam a igualdade de gênero, chamando, cada vez mais, a atenção para os alarmantes números de mulheres vítimas de estupros e para o feminicídio ocorrido em diversos países, a heterogeneidade tem sido uma das marcas bastante significativas das feministas. Assim, não sendo uma formação discursiva homogêna, como, em geral, as FDs não o são, ela se constitui por suas contradições internas, se desdobrando em difererentes facetas do feminismo na luta em favor de determinadas causas específicas de seus movimentos na história - justamente daí surge a importante observação de se falar em feminismos (no plural).

Lançar, desse modo, um olhar analítico sobre um recorte das imagens dos protestos feministas e sobre as posições ocupadas pelos corpos em protesto que nestas imagens se apresentam se revela como um procedimento fundamental, uma vez que tais corpos do femini-n/sm-o compreendem determinados ideais de luta em favor dos direitos das mulheres e, por outro lado, se inscrevem historicamente, produzindo diferentes efeitos de sentido, como o de união entre corpos ocupando marchas e diferentes formas de manifestação (cf. figuras 2, 3 e 5) e também sentidos de tensão e de conflito (cf. figuras 1 e 4).

\section{Os efeitos de sentido no movimento do(s) discurso(s)}

Assim, retornando aos movimentos da história, do final do século XIX até a primeira metade do século XX, na Inglaterra, as feministas que ficaram conhecidas como suffraGETtes ${ }^{8}$ se organizaram pela primeira vez com o objetivo de reivindicar o direito ao voto da mulher. Emily Davison (1872-1913), uma das mulheres que participavam das manifestações feministas nas ruas de Londres, em 1913, foi morta atropelada após se atirar na frente do cavalo do rei Jorge $\mathrm{V}$ - tornando-se ela um dos símbolos daquele movimento feminista inicial.

Desse período, selecionamos para compor nosso corpus uma cena prototípica de protesto feminista que é a do flagrante pelo espectro da câmera de um dos momentos de conflito e de tensão entre diferentes sujeitos (cf. Figura 1) interpelados no/pelo interdiscurso, confrontando, de um lado, a presença de autoridades policiais inglesas exercendo a força contra, de outro lado, o corpo de uma manifestante feminista.

\footnotetext{
${ }^{8} \mathrm{O}$ termo suffragettes - associado ao sentido de sufrágio (o direito de voto) - foi cunhado, em 1906, pelo jornal The Daily Mail para descrever de forma pejorativa as feministas daquela primeira onda. Elas, no entanto, abraçaram a expressão, enfatizando as sílabas GET (obter, conseguir, conquistar - em inglês), afirmando que as suffraGETtes lutariam até conseguir o que queriam.
} 


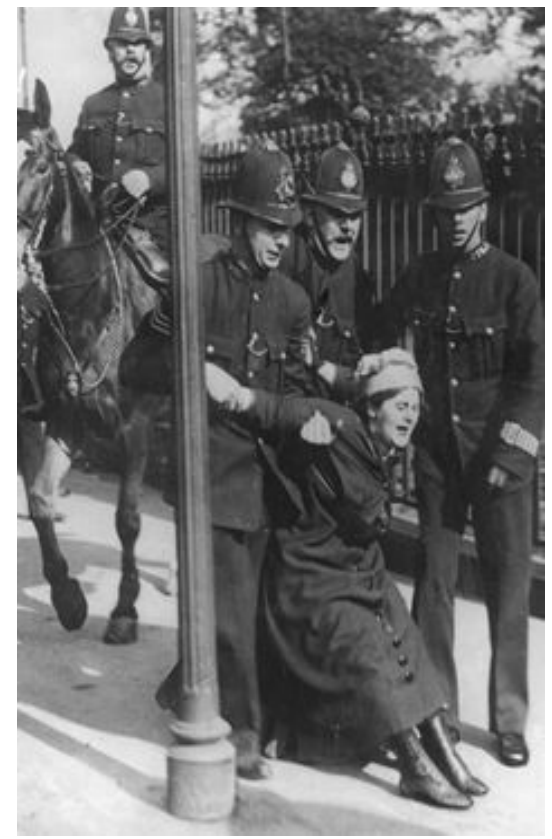

Figura 1. Policiais detêm uma das suffraGETtes, em 1914, em Londres

Nessa imagem, observamos a força exercida por policiais ingleses que detêm uma das suffraGETtes, nas calçadas de rua de Londres, em 1914. A força policial, ao invés de servir de proteção àquela que luta contra a violência pela igualdade e de direitos das mulheres, acaba por utilizar da autoridade e da força de seu corpo para provocar a violência. Em termos discursivos, este corpo outro representa aquilo que Althusser (1970) chama de Aparelho Repressivo de Estado, identificado aqui na repressão ao corpo do femini-n/sm-o em protesto.

O corpo se inscreve a partir de/em uma composição visual cujos limites intra e interdiscursivos são importantes de serem analisados no processo de estruturação do conflito e da tensividade (d)(n)o social. Há, de um lado, o corpo (masculino) que imprime a força pela violência, no movimento de conter o protesto da feminista. De outro lado, há o corpo da feminista que sofre o boicote de seu protesto, e que resiste, porém, tendo os seus braços presos para trás, à força, pelas mãos do outro (os agentes policiais), tendo restringidas a sua liberdade de expressão e a sua atuação dentro do direito de se manifestar politicamente. Corpo autoritário e corpo em protesto entram em combate, deslizando para outros sentidos de opressão e de luta pela liberdade. Conter o protesto desliza metonimicamente para o sentido de conter parte do protesto (que é o corpo). A individualidade e a individuação de corpo do sujeito (manifestante) colocamse nas fronteiras discursivas e ideológicas de repressão ao feminismo.

Pensando o acontecimento da estrutura nas composições visuais, tal como propõe Lagazzi (2014a), é possível observar, a partir ainda dessa imagem (cf. Figura 1), como a formulação visual se desdobra em diferentes imagens do social. Metaforicamente, verifica-se como ela projeta no objeto em foco os sentidos recalcados em condensação - sendo assim, notamos, a partir dessas cenas, uma relação de alteridade pelo processo de deriva. Metonimicamente, ainda de acordo com Lagazzi (2014b), a imagem marca a falta no deslize dos sentidos pela reiteração do close do 
objeto em foco. Há, nesse espectro, um corpo que irrompe, que insurge em protesto e cuja imagem parafrasticamente desliza para outros sentidos convocados pela memória e há o boicote desse corpo e desse protesto no social, ressaltados a tensão e o conflito nessa relação entre o intra e o interdiscurso. Os processos de identificação dos sujeitos se dão, nesse sentido, pelo entrecruzamento dos processos metafórico e metonímico.

É fundamental também apontar as diferentes posições ocupadas pelos sujeitos, indicando sentidos interpelados pela memória e construídos socialmente. Tal como reflete Eni Orlandi (1992, p. 20), "sujeito e sentido se constituem mutuamente, pela sua inscrição no jogo das múltiplas formações discursivas (que constituem as distintas regiões do dizível para os sujeitos)". Há o corpo dos sujeitos que se colocam, através das autoridades policiais, como aparelhos repressivos de Estado. E há o corpo que funciona como suporte do discurso do femini-n/sm-o, ocupando a posição sujeito de manifestante. Manifestante feminina manifestando-se no/pelo feminismo.

\section{Corpos do femini-n/sm-o ocupando os espaços públicos}

$\mathrm{Na}$ análise que aqui empreendemos das imagens do corpo em cenas de protestos feministas, observamos como este se coloca nas fronteiras entre diferentes espaços. Espaços ocupados pelo corpo e espaços do corpo. Espaços que se abrem para sentidos interpelados pela visualidade, pelo gesto e pelo verbal. Sentidos também convocados nos/pelos dizeres inscritos em placas, cartazes e nos corpos das ativistas feministas expostos aos olhos do público.

Consideramos, desse modo, a imbricação entre os efeitos da materialidade verbal e não-verbal (ORLANDI, 1995), tendo em vista as diferentes formas de protestos feministas que compreendem formulações tanto visuais do corpo das mulheres ocupando os espaços públicos, erguendo faixas, cartazes, quanto das formulações materializadas pela discursividade do dizer, muitas vezes, inscritos no próprio corpo feminino, que (re)formula e (res)significa ideologicamente os modos de funcionamento do corpo enquanto suporte discursivo do femini-n/sm-o, atravessado pela história. Nesse sentido, ao analisar o corpo textualizado em diferentes materialidades significantes, Azevedo (2014, p. 322-323) assinala que a própria corporalidade:

[...] é também uma materialidade significante, discursividade inscrita em condições de produção fronteiriças. Se, por um lado, a incompletude (e o movimento que ela instaura) permite o sentido, a errância dos sentidos e dos sujeitos (ORLANDI, 1995), por outro a contradição indica a divisão a que estão sujeitos os objetos ideológicos (PÊCHEUX, 1990). É por isso que a posição materialista exige que se assuma o equívoco e a falha, o silêncio como possibilidade mesma da significação. E isso tem forte relação com a materialidade significante, que deve ser tomada em sua opacidade, em sua não transparência.

Na década de 70, Betty Naomi Goldstein, mais conhecida como Betty Friedan, uma importante ativista feminista norte-americana, liderou a marcha feminista, em 1971, pela aprovação da Emenda de Direitos de Igualdade, nos Estados Unidos. À frente de uma marcha de mulheres (em fila), Betty Friedan, naquela ocasião, segurava um cartaz (cf. Figura 2) com os dizeres em inglês Women need constitutional equality now 
(As mulheres precisam de igualdade constitucional já), seguida de outras ativistas também empunhando cartazes com dizeres protestando em favor dos direitos de igualdade da mulher.

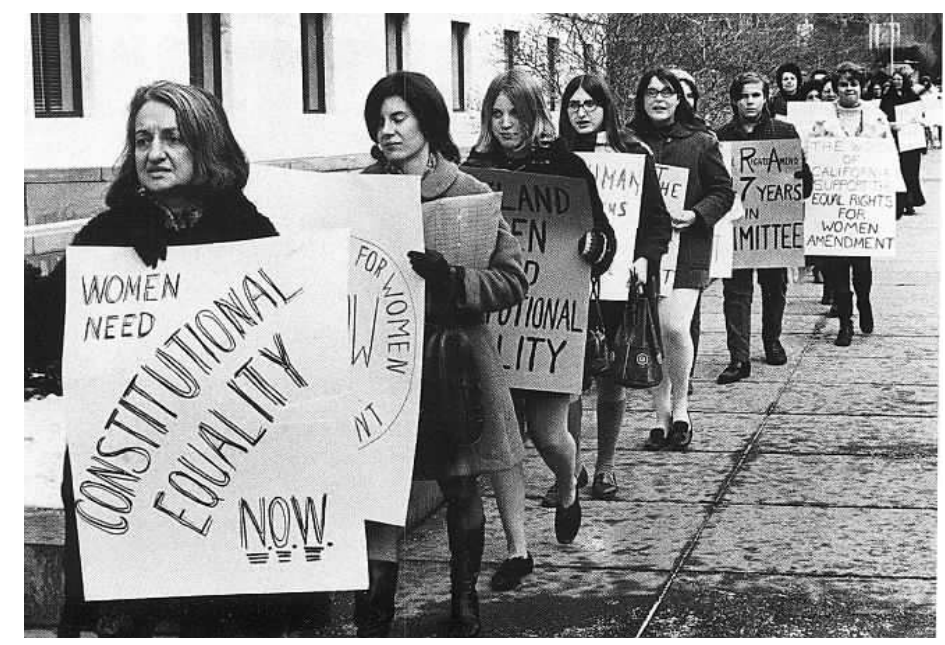

Figura 2. Betty Friedan liderando uma marcha feminista, em 1971, nos EUA

Anterior a esse acontecimento, Betty Friedan já havia se tornado um dos símbolos da luta feminista de seu tempo, quando publicou, em 1963, o seu (à época, polêmico) livro The Feminine Mystique (Mística feminina). Segundo Duarte (2006, p. 287):

[...] o livro, que se tornou best seller nos Estados Unidos, mesmo tendo sido rejeitado, no começo, pela imprensa, discutia a crise de identidade feminina, analisando minuciosamente a construção da imagem da mulher como dona de casa perfeita, mãe e esposa. Tornou-se um dos principais desencadeadores da chamada segunda onda feminista que varreu o Ocidente. A idéia do livro surgiu de um encontro de ex-alunos do Smith College, no qual Betty estudou. Lá, ela comprovou que suas antigas colegas estavam tão insatisfeitas em sua vida doméstica quanto ela, que tinha se casado em 1947 com Carl Friedan, de quem se divorciou em 1969. O "problema mal formulado" ou "mal sem nome" que acometia mulheres, em especial as casadas, nas décadas de 50 e 60, tornou-se perceptível, para Friedan, também a partir de sua própria experiência e da experiência de outras mulheres que ela conheceu em seu trabalho como repórter.

Friedan entrevistou diversas mulheres, buscando compreender suas dificuldades com filhos, casamento, em seus lares e em suas comunidades. Betty Friedan não se conformava com as explicações que circulavam na mídia de sua época que abordavam a infelicidade feminina. Assim ela "resolveu colocar o dedo na ferida ao apontar a 'mística feminina' como causa maior de todos esses problemas que precisariam ser encarados de maneira séria pela sociedade", de acordo com Duarte (Idem, p. 288) - que também destaca que Friedan (Ibidem, p. 289):

[...] analisou, em seu livro, como as mulheres americanas estavam se casando cada vez mais jovens e como iam cada vez menos à universidade, com obsessão durante toda a vida pela condição de objeto belo, preocupando-se em adaptar seu corpo e seu rosto às modas. A cozinha configurava-se como habitat 'natural' da mulher, daí decorrendo todo 
o esforço de decoradores e da indústria de eletrodomésticos para convertê-la em um lugar agradável. O lar, como referência maior, era o lugar de onde as mulheres saíam apenas para comprar, levar as crianças à escola ou acompanhar seus maridos a reuniões sociais.

Desse modo, Friedan (1971 [1963], p. 288) explicava que:

[...] o problema não pode ser compreendido nos termos geralmente aceitos pelos cientistas ao estudarem a mulher, pelos médicos ao tratarem dela, pelos conselheiros que as orientam e os escritores que escrevem a seu respeito. A mulher que sofre deste mal, e em cujo íntimo fervilha a insatisfação, passou a vida inteira procurando realizar seu papel feminino. Não seguiu uma carreira (embora as que o façam talvez tenham outros problemas); sua maior ambição era casar e ter filhos. Para as mais velhas, produtos da classe média, nenhum outro sonho seria possível. As de quarenta ou cinqüenta anos, que quando jovens haviam feito outros planos e a eles renunciado, atiraram-se alegremente na vida de donas-de-casa. Para as mais moças, que deixaram o ginásio ou a faculdade para casar, ou passar algum tempo num emprego sem interesse, este era o único caminho. Eram todas muito "femininas" na acepção comum da palavra, e ainda assim sofriam do mal.

Em outubro de 1966, após a publicação de seu livro, Betty Friedan ajudou a promover, em Washington, uma Conferência Nacional, a partir da qual se constituiu a National Organization for Women ${ }^{9}$ (NOW), que tinha Friedan à frente dessa organização como cofundadora. Faleceu em 4 de fevereiro de 2006, no dia de seu $85^{\circ}$ aniversário, em sua casa, em Washington. Friedan tornou-se, consequentemente, uma das feministas mais influentes do século XX.

Retornando às análises, ainda a partir da Figura 2, observamos como Betty Friedan, diante das inquietações de sua época e da situação da mulher frente à sociedade norte-americana das décadas de 60 e 70, retomou algumas das conquistas de movimentos feministas anteriores e contribuiu para impulsionar, no engajamento político e ideológico, este corpo do femini-n/sm-o para fora dos lares, ocupando os espaços públicos na luta pelos direitos das mulheres, nos Estados Unidos. Corpo e imagem do feminino, assim, se deslocam de dentro para fora (por exemplo, dos lares para as ruas) e de fora para dentro (dos espaços públicos para dentro do movimento feminista). Nesse sentido e em outros é que Lagazzi (2013, p. 110) considera "o investimento no processo de deslinearização da imagem um caminho analítico discursivo produtivo, que pode ainda contribuir significativamente para a abordagem da imagem na relação entre sua materialidade significante e a história". Pensar o corpo em suas projeções enquanto suporte de discurso é também, desse modo, pensar na subjetividade e naquilo que seria essencial no sujeito - e que corresponde à "propriedade de ter sensações de que o eu é antes de qualquer coisa um ser corpóreo, derivando, em última instância, das sensações corporais, podendo-se considerá-lo como uma projeção do corpo" (SOUZA, 2010, p. 4).

\footnotetext{
${ }^{9}$ Em português: Organização Nacional de Mulheres.
} 
Neste exemplo a seguir (cf. Figura 3), podemos também observar como a união de corpos do feminino (em marcha, à frente, atrizes brasileiras ativamente presentes naquela que ficou conhecida como a Passeata dos Cem Mil, ocorrida em 26/06/68, no Rio de Janeiro) constituiu-se como símbolo da resistência feminista contra a ditadura no Brasil, nas décadas de 60, 70 e 80 .

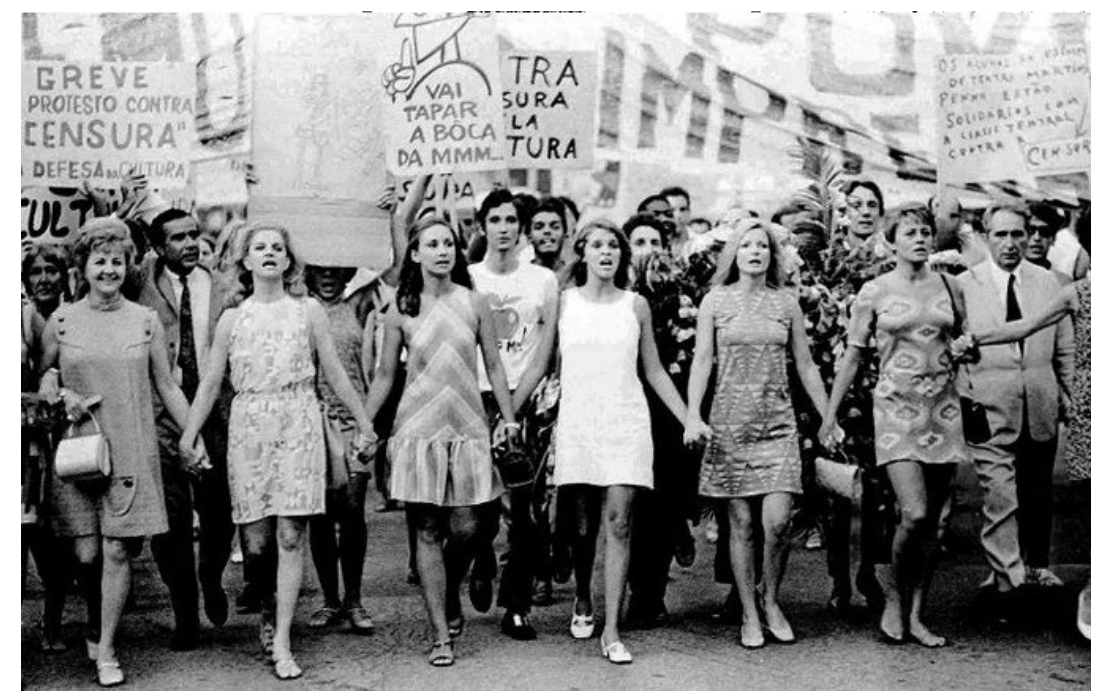

Figura 3. Atrizes brasileiras na "Passeata dos Cem Mil", em 1968, no Rio de Janeiro

Essa imagem capturada pela imprensa brasileira da época ocorreu durante essa manifestação política da Passeata dos Cem Mil, quando a multidão de participantes da passeata já tomava as ruas da Cinelândia, na manhã do dia 26 de junho de 1968, no centro da cidade de Rio de Janeiro (RJ). A marcha contou com a presença de estudantes, artistas, intelectuais, políticos e participantes de outros segmentos da sociedade civil brasileira que se juntaram à passeata. Esta se tornou uma das maiores e mais expressivas manifestações populares da década de sessenta, registrando cerca de 50 mil participantes. Uma hora depois de seu início, segundo dados da imprensa à época, esse número já havia dobrado. Tendo à frente enormes faixas, com diversos dizeres contra a ditadura, a passeata prosseguiu, durante três horas, encerrando-se em frente à Assembleia Legislativa.

$\mathrm{Na}$ imagem em questão, observam-se algumas atrizes brasileiras marchando à frente da multidão, unidas, de mãos dadas. Da esquerda para a direita, na sequência, é possível identificar as atrizes Eva Todor, Tonia Carrero, Eva Wilma, Leila Diniz, Odete Lara e Norma Bengell - formando não apenas uma marcha de mulheres em união, mas uma marcha que se coloca no movimento dos sentidos de luta e resistência contra a opressão (não apenas contra a opressão da ditadura no Brasil, mas contra a ditadura aos direitos da mulher). $\mathrm{O}$ corpo do feminino se coloca discursivamente nas fronteiras entre o social e o político, a partir do gesto de caminhar em união e do gesto de dar as mãos interpelando sentidos pré-construídos de luta do/pelo fortalecimento do feminismo.

Nesse sentido, a cena aqui analisada (na Figura 2) dos corpos do feminino e do feminismo ocupando as ruas norte-americanas, na marcha liderada por Friedan, em 1971, nos EUA, se intercruza com essa última imagem (Figura 3) da Passeata dos Cem 
Mil, no Rio de Janeiro, em 1968. Os sentidos pré-construídos (pelo gesto de sair às ruas em protesto) se estruturam e se atualizam no deslizamento da imagem e na ocupação dos corpos no espaço e no tempo, na relação da memória com a ideologia e com a história, no intra e no interdiscurso. Corpos em marcha, corpos em passeata, corpos de mãos dadas e corpos empunhando cartazes se colocam, assim, nas fronteiras do discurso do femini-n/sm-o, significando a luta, o impulso do movimento de unir-se em direção às conquistas em favor dos direitos da mulher, levando-se em conta o real do corpo, o real da língua e o real da história.

Por estes e outros caminhos é que também podemos compreender como o corpo ocupa discursiva e ideologicamente os espaços, por exemplo, o da praia de Copacabana (cf. Figura 4), deslizando e se abrindo para sentidos convocados e interpelados pela formulação visual e pelos modos de significar e dizer.

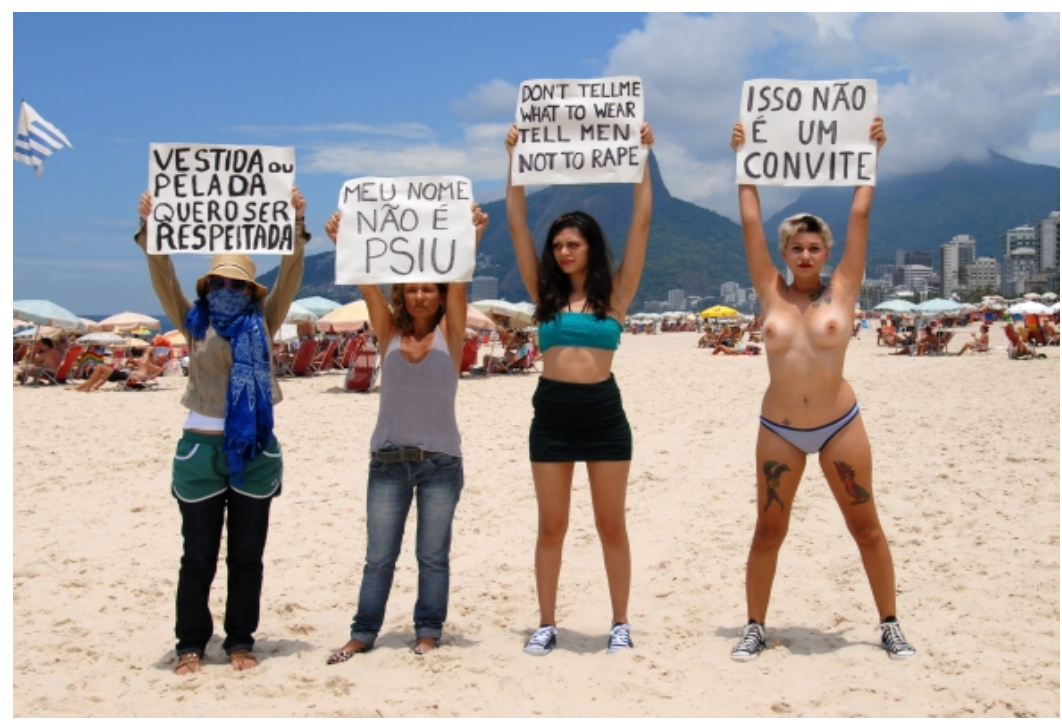

Figura 4. Ativistas do grupo Bastardxs, em 2014, na praia de Copacabana (RJ)

Essa cena prototípica de protesto feminista (ocorrida nas areias da praia de Cobapabana, foi promovida pelo grupo Bastardxs ${ }^{10}$ ) se coloca nas fronteiras entre o espaço ocupado pelo corpo e o discurso do femini-n/sm-o. Alguns dos sentidos mobilizados pelas manifestantes são convocados pelo processo de ressignificação e posicionamento diante de determinadas práticas discursivas (machistas, sexistas) que circulam na sociedade. A discursividade desse protesto é construída a partir do acontecimento que irrompe e atravessa outros sentidos, tais como o de lazer na areia da praia (compreendido por atividades, por exemplo, de descanso, de se bronzear, de tomar sol, de realizar práticas físicas e esportivas, entre outras). Corpo(s) ([re]vestidos d)e sentido(s) se colocam no entremeio entre diferentes formas de significar tanto do corpo

\footnotetext{
${ }^{10}$ No Brasil, o grupo feminista Bastardxs surgiu após o fim do grupo anti-sexista Femen Brazil, liderado por Sara Winter (à direita, na Figura 4). Sara relatou que inicialmente recebeu suporte do Femen internacional, em especial de Alexandra Shevchenko, uma das figuras centrais do grupo na Ucrânia. O autointitulado movimento sextremista Femen Brazil afirmava defender uma forma de oposição ao machismo e também contra a exploração mercantilista da nudez feminina. O grupo sofreu uma reviravolta com o fechamento de sua filial brasileira em menos de um ano depois de sua inauguração. Sara, então, criou junto com outras ativistas o grupo Bastardxs, no qual homens são aceitos.
} 
e das roupas (ou da falta delas) enquanto suportes significantes investidos pela materialidade simbólica, quanto dos dizeres inscritos nos cartazes (re)deslocando e (res)significando outros sentidos.

Lançamos olhar, assim, para o gesto (de levantar os cartazes), para a forma (de as ativistas feministas) se apresentarem corporalmente (cobertas ou não com roupas) e atentamos também para a escolha dos dizeres - inscritos não nos corpos, mas nos cartazes levantados com os braços pelas manifestantes em protesto. A partir da Figura 4, verificamos que tais inscrições são, a saber (da direita para a esquerda): [a] isso não é um convite; [b] don't tell me what to wear, tell men not to rape ${ }^{11}$; [c] meu nome não é psiu; [d] vestida ou pelada quero ser respeitada).

Aqui também observamos a imbricação entre os efeitos da materialidade verbal e não-verbal (ORLANDI, 1995), atravessada por sentidos pré-construídos e cristalizados socialmente que chamam a atenção, nesse caso, por exemplo, para [a] a desconstrução da ideia de que a aparência do corpo feminino (isto é, a mulher estar ou apresentar-se semi-nu[a]), na maioria das vezes, significa um convite seja ele para o sexo, seja ele para situações de sensualidade/erotismo; [b] para a luta contra a ditadura da "beleza" (que dita regras de aparência e formas de se vestir) em contraposição à impunidade de abusos sexuais (estupros) contra mulheres; [c] para a forma como alguns homens tentam vulgarmente "seduzir" (ou chamar a atenção) de algumas mulheres em diferentes espaços (seja por meio de um "psiu"); e [d] para o respeito que as mulheres querem, independente da forma como se apresentam: vestidas, parcialmente vestidas ou não.

Assim, diferentes formas de o corpo do femini-n/sm-o empunhar cartazes em luta pelos direitos das mulheres (como outrora presente na marcha liderada por Betty Friedan, em 1971, nos EUA) se atualizam na/pela memória do discurso feminista, instaurando outras cenas de protesto. A nudez abre espaço para outros sentidos: tanto os seios como parte do corpo da mulher expostos produzem, nos fios do discurso, efeitos de sentido, por exemplo, de indignação contra certas atitudes machistas que invadem a liberdade do outro, ao pré-conceber genericamente que uma mulher nua é um convite explícito e aberto ao sexo. Olhar, desse modo para o corpo pelo viés da $\mathrm{AD}$, demanda do analista um gesto, no batimento entre descrição e interpretação, um olhar que leve em conta o trabalho do simbólico com o político. Tal como nos elucidam muito bem Barbosa Filho e Baldini (2018, p. 7):

[...] isso se deve, sobretudo, pelo fato de que a relação da Análise do Discurso com o materialismo histórico implica, desse modo incontornável, uma relação com o político, com as relações contraditórias e litigiosas que envolvem os sentidos em uma formação social marcada pela divisão.

Nesse sentido, o corpo discursivamente atravessado pela ideologia feminista busca rejeitar e combater tais ideias comuns a determinadas ideologias machistas, diante das diversas facetas que constituem o machismo. Mais do que isto: tal como afirma Fernanda Pereira:

\footnotetext{
${ }^{11}$ Em português: "Não me digam o que vestir, digam para os homens não estruparem!".
} 
$\mathrm{Na}$ atualidade, o sujeito está cercado por uma abundância de linguagem, no qual toda a superfície é tomada por mensagens, imagens, ou seja, tudo significa. [...] Essas marcas, de pertencimento a um grupo que compartilha do discurso pela libertação do corpo da mulher, dão poder aos corpos nus das manifestantes que se constituem, dessa forma, como materialidades discursivas, fazendo então esse sentido circular em diferentes espaços.

Também consideramos importante, desse modo, a questão da temporalidade e da espacialidade, analisando os efeitos de sentido produzidos pelo corpo, no interdiscurso. Atualidade e memória, nesse sentido, intervêm "para enquadrar implicitamente a situação no espaço" (ACHARD, 1999 [1984], p. 12). Os sentidos já ditos n(d)os protestos feministas (na)(ao longo) da História constituem-se de importantes elementos que se estruturam, se dispersam, se estabilizam e se atualizam em uma rede de formulações que se colocam nas tramas da significação por meio dos pré-construídos (PAVEAU, 2013). É a partir disso que tomamos a imagem e a palavra para observar as cenas prototípicas de protestos feministas e os corpos do femini-n/sm-o ocupando os espaços públicos, por meio daquilo que a $\mathrm{AD}$ pretende dar conta: o fato de que algo sempre fala "antes alhures", de acordo com Pêcheux (1975).

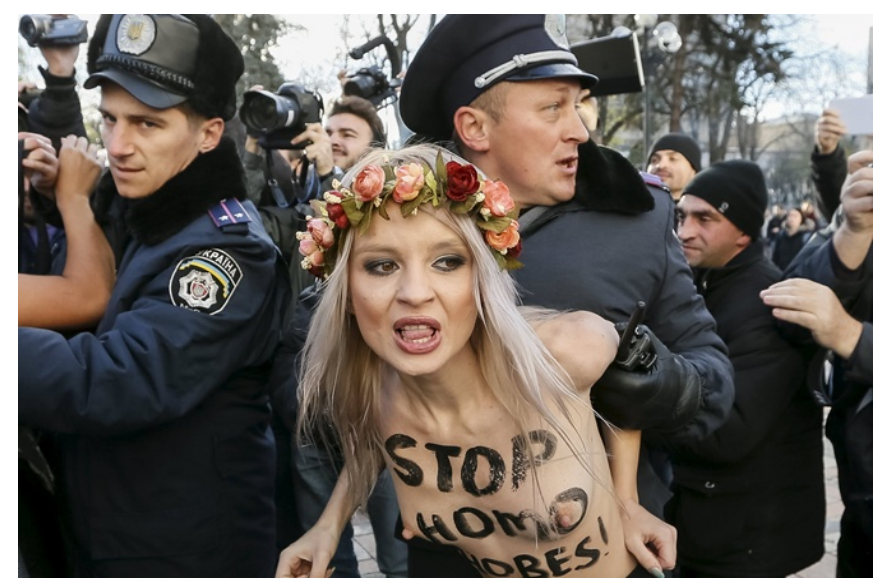

Figura 5. Policiais detêm ativistas do grupo Femen, em 2015, na Ucrânia

A partir dessa imagem (Figura 5), observamos como os sentidos pré-construídos, por conseguinte, se associam ao "sempre-já-aí" da interpelação ideológica que atravessa a história, a memória e a atualidade. Os efeitos de sentido de tensão e de conflito produzidos no/pelo interdiscurso interpelam, neste caso, aquilo que Lagazzi (2013, p. 110) chama de "uma discursivização que fala da equivocidade das formulações visuais do corpo se desdobrando em diferentes imagens do sujeito" e que "fala da tensão entre o sujeito e as condições que o boicotam no social" (Idem, p. 110). Tal como assinala Pereira (2015, p. 234), em uma análise dos protestos do grupo Femen, "as manifestantes normalmente são presas e levadas à força do local, sofrendo maus tratos e abusos". Assim, a atualização do sentido de força policial, utilizada para provocar a violência, ao invés de servir de proteção àquele(a) que luta contra a violência às mulheres, tal como nos protestos feministas, em Londres, em 1914, liderado pelas suffraGETtes (cf. Figuras 1) ou para proteger contra a violência da homofobia (tal como 
convocado pelo dizeres em inglês, Stop homophobes ${ }^{12}$ (inscritos sobre o corpo da manifestante, cf. Figura 5)).

O corpo tomado pelo enunciado significando nas fronteiras com o social um grito contra a homofobia faz irromper o equívoco. Este corpo detido é o corpo que clama pela detenção (pela contenção) dos homofóbicos (e da homofobia na sociedade). Nesse sentido, bem como refletem Baldini e Souza (2012, p. 70):

[...] arcabouço de linguagem, o corpo, em sua errância pelos sentidos é também coberto por essa pele de texto - os gestos, trejeitos, as conformações, a vestimenta, os ornamentos e a inscrição textual. A letra inscrita na carne do sujeito se imiscui em sua pele, realiza seu corpo, conforma sua língua, enforma sua ideologia.

Tais sentidos pelos quais o corpo se inscreve e nele são inscritos instauram, nos fios do discurso, retomadas de sentido que se (re)vestem e/ou se (des)(i)nudam de outros sentidos (res)significados nos movimentos do(s) discurso(s), colocados entre “a estrutura e o acontecimento" (PÊCHEUX, 1990a).

\section{Considerações finais}

No (per)curso dos gestos de interpretação teórico-analítico realizados ao longo de nossas análises, procuramos explicitar o funcionamento discursivo das formulações visuais do corpo do femini-n/sm-o em/no protesto. Observamos como a(s) image-m/ns do corpo na discursividade dos protestos do feminino/feminismo vão produzindo sentidos de luta, de união, de conflito e de resistência, nas fronteiras com o social. Corpo e sentido se movimentam a partir da relação entre a materialidade simbólica, histórica e discursiva, que convoca(m) forças interpeladas pela ideologia. $\mathrm{O}$ corpo feminino é colocado em cena a partir do feminismo, e este se constitui à medida em que os diferentes sentidos do feminino e do feminismo se intercruzam na história, a partir do movimento dos sentidos em torno da materialidade significante do corpo e na relação corpo-memória-discurso presentes nas imagens que circulam ao longo da história, desde os protestos feministas das chamadas suffraGETtes, em Londres, na virada do século XIX para o século XX, até os protestos feministas dos dias atuais (da chamada quarta onda feminista).

Nesse sentido, analisamos a imbricação entre os efeitos das materialidades verbal e não-verbal, a partir da discursividade dos protestos feministas, na corporalidade que se coloca nas fronteiras do gesto e do dizer - como observado pelas palavras "Marine féministe fictive!" inscritas sobre o corpo da manifestante do grupo Femen. Este acontecimento simbólico e discursivo, que transcende as fronteiras do corpo e dos espaços por ele ocupado, se constitui como ruptura das formulações do sentido enquanto forma de negação do discurso político do outro. Sob diferentes formulações verbais e não-verbais, o dizer se coloca nas fronteiras do sentido, construído no intra e no interdiscurso. O corpo se coloca em jogo em uma cena prototípica de protesto, cuja composição visual marca limites intra e interdiscursivos sensíveis, importantes de serem analisados no processo de estruturação do conflito e da tensividade (d)(n)o social.

\footnotetext{
${ }^{12}$ Em português: "Detenham os homofóbicos!".
} 
Imagem, memória, ideologia e discurso se formulam e se atualizam em uma relação aberta entre a estrutura e o acontecimento. Acontecimento este atravessado pela linguagem ocupando diferentes espaços de significação, de luta e de resistência, bem como diferentes corpos em protesto, produzindo efeitos de sentido nas fronteiras entre o femini-n/sm-o e a história.

\section{REFERÊNCIAS}

ACHARD, P. Memória e produção discursiva do sentido. In: ACHARD, P.; PÊCHEUX, M. et al. Papel da memória. Tradução de José Horta Nunes. Campinas: Pontes, 1999 [1984].

ALTHUSSER, L. Idéologie et appareils idéologiques d'État. La Pensée, n. 151, p. 3-38, juin. 1970.

AZEVEDO, A. F. Sentidos do corpo: metáfora e interdiscurso. Linguagem em (Dis)curso, v. 14, n. 2, p. 321-335, 2014.

BALDINI, L. J. S.; SOUZA, L. L. Os sentidos tomando corpo. In: AZEVEDO, A. F. (Org.). Sujeito, corpo e sentido. Curitiba: Appris, 2012. p. 69-88.

BARBOSA FILHO, F. R.; BALDINI, L. J. S. Prática política e materialidades. In: . (Org.). Análise de discurso e materialismos: prática política e materialidades.

Campinas: Pontes, v. 2, p. 7-8, 2018.

BEAUVOIR, S. Le deuxième sexe. Paris: Gallimard, 1949.

BLAY, E. A. Um caminho ainda em construção: a igualdade de oportunidades para as mulheres. Revista USP, v. 49, p. 82-97, 2001.

BRETON, D. L. A sociologia do corpo. Petrópolis: Vozes, 2007.

DUARTE, A. R. F. Betty Friedan: morre a feminista que estremeceu a América. Revista Estudos Feministas, v. 14, n. 1, p. 287-293, 2006.

FRANÇA, G. R. A. Sobre (e n)o corpo: o discurso do turismo sexual nos ambientes digital e off-line. Caderno de estudos do discurso e do corpo, v. 10, n. 2, p. 81-98, 2016.

GARCIA, D. A. Quarta onda feminista: a mulher e o ciberespaço. In: Caderno de resumos do IX Encontro Internacional Saber Urbano e Linguagem: escrituras da cidade. Labeurb-Unicamp, Campinas, p. 25-26, 2018.

FRIEDAN, B. Mística feminina. Petrópolis: Vozes, 1971 [1963].

HAROCHE, C.; GUGLIELMI, G. J. Esprit de corps, démocratie et espace public. Paris: Presses Universitaires de France (PUF), 2005.

LAGAZZI, S. A imagem do corpo no foco da metáfora e da metonímia. REDISCO Revista Eletrônica de Estudos do Discurso e do Corpo, v. 2, n. 1, p. 104-110, 2013.

- Metaforizações metonímicas do social. In: ORLANDI, E. (Org.). Linguagem, sociedade, politicas. Campinas: RG Editores, 2014a. p. 105-112. 
- A deslinearização em diferentes materialidades significantes. In: $X X I X$ Encontro Nacional da ANPOLL, GT de Análise do Discurso. Florianópolis: UFSC, 2014b.

ORLANDI, E. Análise de discurso: princípios e procedimentos. Campinas: Pontes, 1990.

. As formas do silêncio: no movimento dos sentidos. Campinas: Ed. UNICAMP, 1992.

. Efeitos do verbal sobre o não verbal. Rua (UNICAMP), v. 1, n. 1, p. 35-47, 1995.

. La ville comme espace politique-symbolique. Des paroles désorganisées au récit urbain. Langage et societé, n. 96, p. 105-127, 2001.

. Processos de significação, corpo e sujeito. In: ORLANDI, E. Discurso em Análise: sujeito, sentido, ideologia. 2. ed. Campinas: Pontes, 2012. p. 83-96.

PAVEAU, M-A. Os pré-discursos: sentido, memória, cognição. Campinas: Pontes, 2013.

Quand les corps s'écrivent. Discours de femmes à l'ère du numérique. In:

BIDAUD, É. (Dir.). Recherches de visages. Une approche psychanalytique. Paris: Hermann, 2014. p. 207-241.

PAHUD, S.; PAVEAU, M-A. Féminismes de quatrième génération. Textes, corps, signes. Appel à articles pour la revue Itinéraires - Littérature Textes Cultures, 2016.

PÊCHEUX, M. Les vérités de la Palice. Paris: Maspero, 1975.

. Rôle de la mémoire. In: ACHARD, P.; GRUENAIS, M. P.; JAULIN, D. (Éds). Histoire et Linguistique, Actes de la table ronde "Langage et Societé ". Paris: Editions de la Maison des Sciences de l'Homme, 28-29-30 avril 1983, 1984. p. 261-267.

Campinas: Pontes, 1990a.

. Delimitações, inversões e deslocamentos. Tradução de José Horta Nunes. $\overline{\text { Cadernos }}$ de Estudos Linguísticos, v. 19, p. 7-24, 1990b [1982].

PEREIRA, F. Guerreiras do FEMEN: uma análise dos efeitos de sentido produzidos pelas imagens. In: Anais do I Congresso Internacional da Linguística Aplicada Crítica: linguagem, ação e transformação. v. 1. Londrina: UEL, 2015. p. 228-241.

Corpos em protesto: uma análise discursiva do movimento Femen. 2017. 163 f. Dissertação (Mestrado em Letras) - Centro de Educação, Comunicação e Artes, Universidade Estadual do Oeste do Paraná, Cascavel, 2017.

Recebido em: 20/08/2017

Aprovado em: 19/06/2018 